\title{
Non-contact Dynamic Capacity-Increasing of Overhead Conductor Based on Cooling Tester (CT)
}

\author{
Rui Wang ${ }^{1}$, Ruidong Peng ${ }^{2 *}$, Xiangyang Peng ${ }^{1}$, Zhao Liu ${ }^{2}$, Jiajian Huang ${ }^{1}$, Wencheng Zheng ${ }^{2}$ and Gang Liu ${ }^{2}$ \\ ${ }^{1}$ Electric Power Research Institute of Guangdong Power Grid Co., Ltd., Guangzhou, Guangdong, 510080, China \\ ${ }^{2}$ School of Electric Power Engineering, South China University of Technology, Guangzhou, Guangdong, 510640, China
}

\begin{abstract}
The traditional dynamic capacity-increasing technology of overhead conductors needs to monitor the operation state of conductors (temperature, sag, etc.), and the relevant sensors are usually installed directly on the surface of conductors. The installation cost is high, and the operating maintenance is complicated. In this paper, a non-contact dynamic capacity-increasing method for overhead conductors based on CT is proposed. Firstly, the theory of the non-contact dynamic capacity-increasing method for conductors is introduced, and a cooling testing device is designed according to the theory. Then, the cooling index is defined to represent the cooling capacity of the object, and the corresponding cooling indexes for the conductors and the $\mathrm{CT}$ are calculated based on the steady-state thermal balance equation. By establishing a cooling correlation model for the conductors and the CT, the calculation for the dynamic ampacity of the conductors can be obtained. Finally, the cooling conditions of cooling testing device at different ambient temperatures and wind speeds are calculated through the finite element simulation method. Combined with the dynamic capacityincreasing method proposed in this paper, the corresponding ampacity value are obtained, and the effect of capacity increase is analyzed. The results show that the non-contact dynamic capacity-increasing method based on the CT has obvious effect in capacity-increasing compared with the static ampacity.
\end{abstract}

\section{Introduction}

The demand for electricity is increasing with the rapid growth of society and economy. The existing transmission corridor density and scale of power grid are already exceptionally large. For developed regions, it is incredibly challenging to set up a new transmission corridor because of the existing large-scale and high-density transmission corridor. Therefore, how to improve the potential transmission capacity scientifically and safely in the current transmission corridor is an urgent problem to be solved.

At present, the methods of capacity-increasing for overhead conductors at home and abroad include the static capacity-increasing technology and the dynamic capacityincreasing technology. Among them, the static capacityincreasing technology can increase the conductor ampacity by increasing the conductor's temperature tolerance level. In addition, instead of breaking the current procedures, the dynamic capacity-increasing technology calculates the real-time ampacity of the conductors based on different models (climate model, conductor temperature model, tension model, thermal circuit model, etc.) through real-time monitoring on the conductor state and meteorological environment[1-2]. Compared with the static capacity-increasing technology, there is more potential in exploiting the transmission capacity of conductors in the dynamic capacity-increasing technology. At the same time, the existing dynamic capacityincreasing technology still has some shortcomings. The dynamic capacity-increasing technology based on the climate model needs to monitor the environmental parameters (wind speed, environmental temperature, sunshine, etc.). However, due to the low measurement accuracy of the environmental parameters, the error of the calculation result for ampacity is large. The dynamic capacity-increasing technology based on the conductor temperature model, the tension model and the thermal circuit model requires the installation of temperature sensor or tension sensor on the conductor surface, but the installation cost for the corresponding sensors is high and the later maintenance is difficult[3-6]. Aiming at these problems above, a non-contact dynamic capacityincreasing method based on CT is proposed in this paper. With no installing additional sensors required on the conductor surface, the cooling condition of the CT is associated with the cooling condition of conductors to significantly improve the feasibility of the dynamic capacity-increasing technology.

In this paper, the principle of the non-contact dynamic capacity-increasing method based on CT is described at first, and the structure of CT and the functions of each part are introduced. Then, the cooling index is defined to represent the cooling condition of the object, and the

*Corresponding author's e-mail: 277720292@qq.com 
correlation model for the conductors and the CT is obtained through the theoretical analysis from the cooling index of the conductors and the CT. According to the model, the dynamic ampacity of conductors is calculated. Finally, the finite element simulation method is used to simulate the cooling condition of the CT under different environmental conditions. Based on the dynamic capacityincreasing method proposed in this paper, the corresponding ampacity value is calculated, and the capacity-increasing effect is analyzed and discussed.

\section{Non-contact dynamic capacity- increasing method}

\subsection{Theory of non-contact dynamic capacity- increasing}

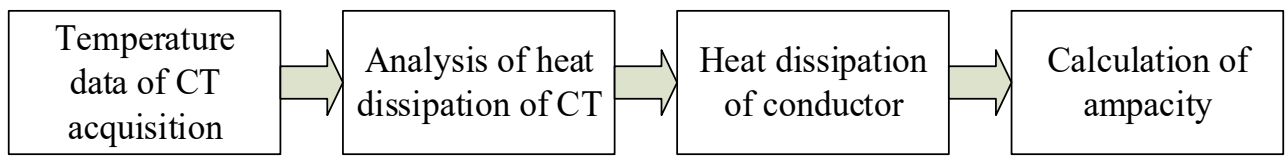

Fig.1 Process of non-contact dynamic capacity-increasing method based on cooling testing device

\subsection{Cooling testing device}

Based on the principle of non-contact dynamic capacity increase, a cooling testing device is designed. The cooling testing device includes the CT, controller, temperature rising device, temperature measuring device, data sending unit, data storage unit, and environmental monitoring unit. The principle of the cooling testing device is shown in Fig.2(a). From Fig.2(a), the temperature rising device heats up the CT through the resistance wire under the command of the controller. The temperature measuring device uses a thermocouple to measure the temperature, and the thermocouple is laid on the surface of the CT (four temperature measuring points are set, and the average temperature of the tester is calculated). The environmental
The non-contact dynamic capacity-increasing method is basically to place the CT in the same air environment as the conductors and apply a constant heat source to heat it up. After a certain time, the CT reaches a steady state, and the temperature no longer changes. A temperature measurement device is used to collect the temperature data of the CT, and the cooling situation of the CT is analyzed in combination with the actual environmental conditions (wind speed, environmental temperature, etc.). According to the cooling correlation model for the CT and the conductors, the conductor cooling condition can be obtained by the cooling condition of the CT. Finally, the real-time conductor ampacity is calculated by the thermal balance equation. Fig. 1 is the process diagram of the noncontact dynamic capacity increase.

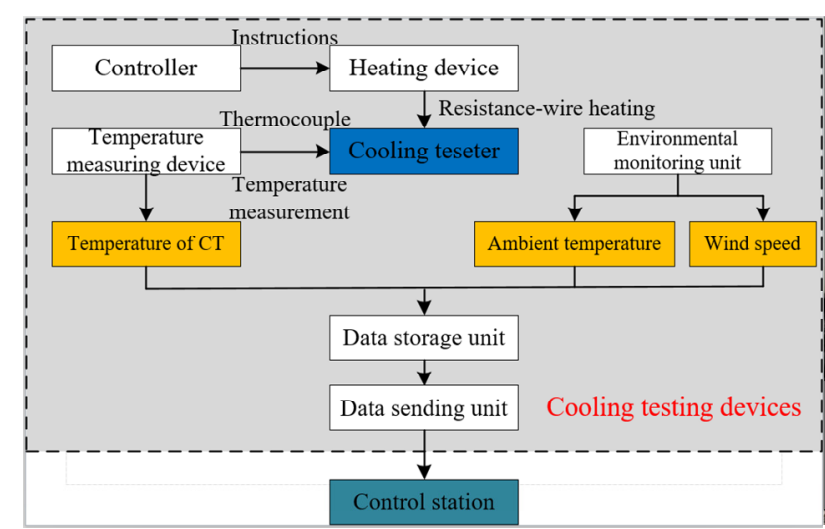

(a) Device schematic diagram monitoring unit can collect the real-time environmental temperature and wind speed. The collected temperature data and environmental data of the CT are stored through the data storage unit and being sent to the ground receiver through the data sending unit. Fig. 2(b) is a physical drawing of the cooling testing device.

As an important part of the cooling test device, the CT should meet the following two requirements:

1) The heating process must be relatively fast to reduce the impact of environmental changes on the accuracy.

2) During the heating process, the entire CT should be heated evenly, so that the temperature measurement for the CT will not have much error.

With the two points above, also considering the outer strand of conductors is made of aluminum, the aluminum ball is selected as the CT.

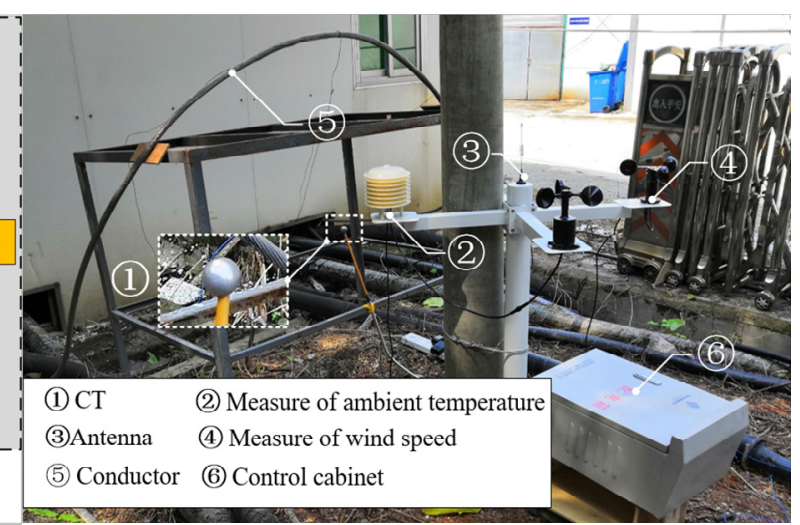

(b) Device physical drawing

Fig. 2 Cooling testing device 


\section{Theoretical derivation of cooling correlation model}

The non-contact dynamic capacity-increasing method is based on the cooling correlation model to calculate ampacity. This chapter will carry out the theoretical derivation of the cooling model and explore the cooling correlation between the $\mathrm{CT}$ and the conductors.

\subsection{Definition of cooling index}

To quantitatively describe the cooling condition of an object, a cooling index is defined to characterize the cooling capacity of the object under certain environmental conditions. The cooling index $\alpha$ of an object means that the sum of the total heat loss from the surface of an object per unit surface area is proportional to the temperature difference between the surface of the object and the air, that is:

$$
\alpha=\frac{W_{\text {total }}}{A \cdot\left(T_{\mathrm{o}}-T_{\mathrm{a}}\right)}
$$

where, $\alpha$ is the cooling index of the object, $\mathrm{W} /\left(\mathrm{m}^{2} \cdot \mathrm{K}\right)$; $W_{\text {total }}$ is the total cooling power of the object, $\mathrm{W} ; A$ is the surface area of the object, $\mathrm{m}^{2} ; T_{\mathrm{o}}$ is the surface temperature of the object, $\mathrm{K} ; T_{\mathrm{a}}$ is the ambient temperature, $\mathrm{K}$.

According to the definition of cooling index, we can get equations (2) and (3):

$$
\begin{gathered}
\alpha_{\mathrm{c}}=\frac{W_{\text {total, } \mathrm{c}}}{\pi \cdot D \cdot\left(T_{\mathrm{c}}-T_{\mathrm{a}}\right)} \\
\alpha_{\mathrm{b}}=\frac{W_{\text {total, } \mathrm{b}}}{4 \pi r^{2} \cdot\left(T_{\mathrm{b}}-T_{\mathrm{a}}\right)}
\end{gathered}
$$

where, $\alpha_{\mathrm{c}}$ is the cooling index of the conductor, $\mathrm{W} /\left(\mathrm{m}^{2} \cdot \mathrm{K}\right)$; $\alpha_{\mathrm{b}}$ is the cooling index of the $\mathrm{CT}, \mathrm{W} /\left(\mathrm{m}^{2} \cdot \mathrm{K}\right) ; \mathrm{W}_{\text {total, } \mathrm{c}}$ is the total cooling power of the conductor per unit length, $\mathrm{W} / \mathrm{m}$; $W_{\text {total, b }}$ is the total cooling power of the CT, W; $D$ is the diameter of the conductor, $\mathrm{m} ; T_{\mathrm{c}}$ is the surface temperature of the conductor, $\mathrm{K} ; r$ is the radius of the aluminum ball, $\mathrm{m} ; T_{\mathrm{b}}$ is the temperature on the surface of the CT, K.

\subsection{Conductor cooling index}

The steady-state thermal balance equation of the conductors is shown in equation (4):

$$
I^{2} R\left(T_{\mathrm{c}}\right)+W_{\mathrm{s}, \mathrm{c}}=W_{\mathrm{c}, \mathrm{c}}+W_{\mathrm{r}, \mathrm{c}}=W_{\text {total, } \mathrm{c}}
$$

where, $I$ is the current value flowing through the conductors, $\mathrm{A} ; R\left(T_{\mathrm{c}}\right)$ is the conductor ac resistance per unit length under $T_{\mathrm{c}}$ temperature $\Omega / \mathrm{m} ; W_{\mathrm{s}, \mathrm{c}}$ is the solar heat absorption power of conductors per unit length, $\mathrm{W} / \mathrm{m} ; W_{\mathrm{r}}$, $c$ is the radiant cooling power of conductors per unit length, $\mathrm{W} / \mathrm{m} ; W_{\mathrm{c}, ~ c}$ is the convective cooling power of the conductors per unit length, $\mathrm{W} / \mathrm{m}$.

Because the conductors are at a high altitude $(20-40 \mathrm{~m})$, it is often blown by wind, forming forced convection heat transfer. According to the IEEE standard, the forced convection cooling power $W_{\mathrm{c}, \mathrm{c}}$ of conductors per unit length satisfies the relation equation (5) :

$$
W_{\mathrm{c}, \mathrm{c}}=\left[1.01+1.35(\mathrm{Re})^{0.52}\right] k_{f} K_{\text {Angle }}\left(T_{\mathrm{c}}-T_{\mathrm{a}}\right)
$$

where, Re represents the Reynolds number; $k_{f}$ is the thermal conductivity of air, $\mathrm{W} /(\mathrm{m} \cdot \mathrm{K}) ; K_{\text {Angle }}$ is the wind Angle coefficient. As for $k_{f}$ and $K_{\text {Angle }}$ can be found in the IEEE Std 738-2012.

In addition, according to the IEEE standard, the radiant cooling power $W_{\mathrm{r}, \mathrm{c}}$ and sunshine radiant power $W_{\mathrm{s}, \mathrm{c}}$ of conductor per unit length can be expressed in the following equations:

$$
\begin{gathered}
W_{\mathrm{r}, \mathrm{c}}=\pi D \sigma \varepsilon\left[\left(T_{\mathrm{c}}+273\right)^{4}-\left(T_{\mathrm{a}}+273\right)^{4}\right] \\
W_{\mathrm{s}, \mathrm{c}}=\beta \cdot J \cdot D
\end{gathered}
$$

where, $\varepsilon$ is the emissivity; $\sigma$ Is the Stephen-Boltzmann constant with a value of $5.67 \times 10^{-8} \mathrm{~W} /\left(\mathrm{m}^{2} \cdot \mathrm{k}^{4}\right) ; \beta$ is the absorption coefficient, generally $0.3-0.35$ is for the new line and $0.9-0.95$ is for the old line; $J$ is the sunshine radiation intensity, $\mathrm{W} / \mathrm{m}^{2}$.

In combination with equation (2), the cooling index of the conductors can be calculated by the heat dissipation end and the heat generation end of the thermal balance equation, respectively. The cooling index calculated according to the heat dissipation end is:

$$
\alpha_{\mathrm{c}}=\varepsilon \sigma \cdot\left[\left(T_{\mathrm{c}}+273\right)^{2}+\left(T_{\mathrm{a}}+273\right)^{2}\right] \cdot\left[\left(T_{\mathrm{c}}+273\right)+\left(T_{\mathrm{a}}+273\right)\right]+\frac{\left[1.01+1.35(\mathrm{Re})^{0.52}\right] k_{f} K_{\text {Angle }}}{\pi D}
$$

The cooling index calculated by the heat generation end is:

$$
\overline{\alpha_{c}}=\frac{I^{2} R\left(T_{c}\right)+W_{s c}}{\pi D\left(\mathrm{~T}_{c}-\mathrm{T}_{a}\right)}
$$

\subsection{Cooling index of aluminum ball CT}

The thermal balance equation of the aluminum ball is

$$
W_{\text {self }}+W_{\mathrm{s}, \mathrm{b}}=W_{\mathrm{c}, \mathrm{b}}+W_{\mathrm{r}, \mathrm{b}}=W_{\text {total, } \mathrm{b}}
$$

where, $W_{\text {self }}$ is the heat source power of the aluminum ball cooling testing device, $\mathrm{W} ; W_{\mathrm{s}, \mathrm{b}}$ is the solar heat absorption power of the aluminum ball $\mathrm{CT}, \mathrm{W} ; W_{\mathrm{c}, \mathrm{b}}$ is the convective cooling power of the aluminum ball $\mathrm{CT}, \mathrm{W} ; \mathrm{W}_{\mathrm{r}, \mathrm{b}}$ is the radiant cooling power of the aluminum ball $\mathrm{CT}, \mathrm{W}$.

According to the formula of radiant cooling in heat transfer theory, the radiant cooling power of the aluminum ball CT can be deduced as:

$$
W_{\mathrm{r}, \mathrm{b}}=4 \pi r^{2} \varepsilon \sigma\left[\left(T_{\mathrm{b}}+273\right)^{4}-\left(T_{\mathrm{a}}+273\right)^{4}\right]
$$

According to the experimental correlation formula for the forced convective cooling of the fluid passing over the sphere in heat transfer, the convective cooling power of the aluminum ball $\mathrm{CT}$ can be deduced as: 


$$
W_{\mathrm{c}, \mathrm{b}}=\frac{N u \cdot K_{f}}{l}\left(T_{\mathrm{b}}-T_{\mathrm{a}}\right)
$$

where, $l$ is the characteristic length, and the diameter of the sphere is used, $\mathrm{m} ; \mathrm{Nu}$ is the number of Nusselt number, which satisfies the following equation:

$$
\left\{\begin{array}{l}
N u=2+\left(0.4 \mathrm{Re}^{1 / 2}+0.06 \operatorname{Re}^{2 / 3}\right) \operatorname{Pr}^{0.4}\left(\frac{\mu_{\infty}}{\mu_{w}}\right)^{1 / 4} \\
\operatorname{Pr}=\frac{\eta_{\infty} C_{\mathrm{p}}}{k_{f}}
\end{array}\right.
$$

where, Pr is Prandtl number; $\mu_{\infty}$ and $\mu_{\mathrm{w}}$ respectively represent the dynamic viscosity of the air environment and the dynamic viscosity of the air on the surface of the sphere, $\mathrm{Kg} /(\mathrm{m} \cdot \mathrm{s}) ; \mathrm{C}_{\mathrm{P}}$ is the specific heat capacity of air, $\mathrm{J} /$ $(\mathrm{kg} \cdot \mathrm{K})$.

The solar heat absorption power of the aluminum ball satisfies equation (14):

$$
W_{\mathrm{s}, \mathrm{b}}=\beta \cdot 2 \pi r^{2} \cdot J
$$

In combination with equation (3), the cooling index of the aluminum ball can be calculated through the heat dissipation end and the heat generation end of the heat balance equation, respectively. The cooling index calculated by the heat dissipation end is:

$\alpha_{b}=\varepsilon \sigma\left[\left(T_{\mathrm{b}}+273\right)^{2}+\left(T_{\mathrm{a}}+273\right)^{2}\right]\left[\left(T_{\mathrm{b}}+273\right)+\left(T_{\mathrm{a}}+273\right)\right]+\frac{N u \cdot K_{f}}{l}$

The cooling index calculated by the heat generation end is:

$$
\overline{\alpha_{b}}=\frac{W_{\mathrm{self}}+W_{\mathrm{s}, \mathrm{b}}}{4 \pi r^{2}\left(\mathrm{~T}_{b}-\mathrm{T}_{a}\right)}
$$

\subsection{Ampacity calculation based on cooling correlation model}

Combining equations (8) and (15), the cooling index correlation function of the conductors and the aluminum ball CT is concluded as follows:

$$
F\left(V, T_{\mathrm{a}}, T_{\mathrm{c}}, T_{b} \ldots\right)=\frac{\alpha_{\mathrm{c}}}{\alpha_{\mathrm{b}}}
$$

According to the current procedure, the current ampacity of conductors is the maximum current flowing through the conductors at a temperature of $70{ }^{\circ} \mathrm{C}$. Therefore, according to equation (9), equation (16) and equation (17), the calculation equation for ampacity is obtained as follow:

$$
I=\sqrt{\frac{\pi D F \overline{\alpha_{\mathrm{b}}}\left(70-T_{a}\right)-W_{\mathrm{sc}}}{R\left(70{ }^{\circ} \mathrm{C}\right)}}
$$

Equation (18) can be used to correlate the cooling index of the aluminum ball $\mathrm{CT}$ to the calculation of ampacity so as to realize the capacity increase scheme in Fig. 1.

\section{Non-contact dynamic capacity increase effect analysis based on finite element}

In this chapter, the Comsol software is used to construct a three-dimensional fluid temperature field simulation model of aluminum ball $\mathrm{CT}$ and simulate the cooling conditions of aluminum ball under different ambient temperatures and wind speeds. Based on the simulation results, the cooling indexes of the aluminum ball under different environment are calculated, and the ampacity of the corresponding conductors (taking the new conductor of model LGJ-240/30 as an example) is calculated through the method proposed in this paper.

\subsection{Cooling simulation analysis for aluminum ball CT}

Fig. 3 shows the geometric simulation model of the aluminum ball CT. As shown in Fig. 3, the aluminum ball is placed in the sphere of air. According to equation (16), the radius of the aluminum ball should not be too large or too small, otherwise the calculation accuracy of ampacity will be affected. Here, the diameter of the aluminum ball is similar to that of the target conductor, which is $20 \mathrm{~mm}$. To reduce the calculation amount of the simulation model and ensure that the simulation results are consistent with the reality, the radius of the spherical air domain is set as $150 \mathrm{~mm}$, and the boundary of the air domain is open, so as to eliminate the temperature distribution error caused by the size of the air domain.

In addition, the heat source of the aluminum ball $\mathrm{CT}$ is set at $300 \mathrm{~kW} / \mathrm{m}^{3}$. For the convective heat transfer between the aluminum ball CT and the surrounding air, a nonisothermal flow in Comsol is applied by means of fluidsolid coupling. The radiation on the solid heat transfer module surface to the environment is used to realize the radiant heat dissipation between the aluminum ball $\mathrm{CT}$ and the surrounding environment, and an external radiation source in the solid heat transfer module is used to simulate the solar radiation heat absorption of the aluminum ball CT (here the sunshine intensity is set to $1000 \mathrm{~W} / \mathrm{m}^{2}$ ). Since the aluminum balls in the cooling testing device are easy to replace, the radiation coefficient and absorption coefficient of the aluminum ball CT both are set with new balls (both set as 0.3).

In the above simulation model, the different environmental conditions are simulated by adjusting the ambient temperature and wind speeds in this paper, and the temperature distribution of the aluminum ball CT under different conditions are calculated. Fig. 4 shows the two-dimensional cross-section temperature distribution cloud diagram of the aluminum ball $\mathrm{CT}$ (the ambient temperature is $20^{\circ} \mathrm{C}$, and the wind speed is $1 \mathrm{~m} / \mathrm{s}$ ). It is found in Fig. 4 that the surface temperature distribution of the aluminum ball is uneven due to the air flow around it. Among them, the highest temperature on the surface of the aluminum ball is located on the leeward side, while the lowest temperature on the surface of the aluminum ball is located on the windward side. 


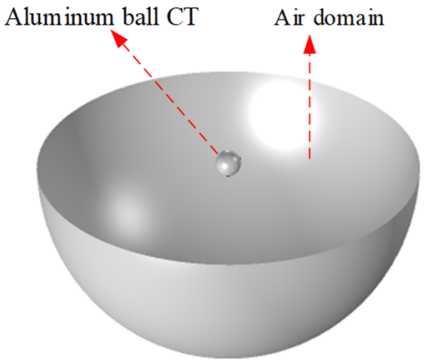

Fig. 3 Simulation model of aluminum ball CT

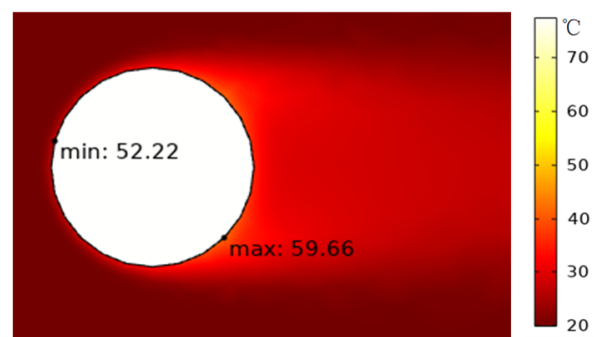

Fig. 4 Temperature distribution of 2D cross-section of aluminum ball (ambient temperature is $20^{\circ} \mathrm{C}$, wind speed is $1 \mathrm{~m} / \mathrm{s})$

\subsection{Analysis for cooling index and capacity- increasing effect of aluminum balls under different environmental conditions}

In the cooling index calculation, the average surface temperature of the aluminum ball is used as the temperature of the CT. Table 1 shows the calculation results for the cooling index of aluminum ball under different environmental conditions.

Table 1 Calculation results for cooling index of aluminum ball

\begin{tabular}{cccc||cccc}
\multicolumn{7}{c}{ under different conditions } \\
\hline $\mathbf{V} /(\mathbf{m} / \mathbf{s})$ & $\boldsymbol{T}_{\mathbf{a}} / \mathbf{K}$ & $\boldsymbol{T}_{\mathbf{b}} / \mathbf{K}$ & $\boldsymbol{\alpha}_{\mathbf{b}}$ & $\mathbf{V} /(\mathbf{m} / \mathbf{s})$ & $\boldsymbol{T}_{\mathbf{a}} / \mathbf{K}$ & $\boldsymbol{T}_{\mathbf{b}} / \mathbf{K}$ & $\boldsymbol{\alpha}_{\mathbf{b}}$ \\
\hline 1.0 & 20 & 56.13 & 31.82 & 2.0 & 20 & 42.29 & 51.57 \\
1.0 & 25 & 61.36 & 31.62 & 2.0 & 25 & 47.43 & 51.25 \\
1.0 & 30 & 66.59 & 31.42 & 2.0 & 30 & 52.57 & 50.93 \\
1.0 & 35 & 71.81 & 31.23 & 2.0 & 35 & 57.71 & 50.63 \\
1.0 & 40 & 77.03 & 31.04 & 2.0 & 40 & 62.84 & 50.32 \\
1.5 & 20 & 47.24 & 42.20 & 2.5 & 20 & 39.09 & 60.23 \\
1.5 & 25 & 52.41 & 41.94 & 2.5 & 25 & 44.21 & 59.85 \\
1.5 & 30 & 57.58 & 41.68 & 2.5 & 30 & 49.33 & 59.49 \\
1.5 & 35 & 62.74 & 41.44 & 2.5 & 35 & 54.44 & 59.13 \\
1.5 & 40 & 67.91 & 41.19 & 2.5 & 40 & 59.56 & 58.78 \\
\hline
\end{tabular}

From Table 1, when the wind speed is constant, the cooling index of the aluminum ball gradually decreases with the increase of the ambient temperature. When the ambient temperature is constant, the cooling index of the aluminum ball gradually increases with the increase of wind speed. The higher the cooling index is, the better the current environment condition is. Compared with the influence of wind speed on cooling index, the influence of ambient temperature on cooling index is extremely small. This is because at different ambient temperatures, the difference between the surface temperature of the aluminum ball and the ambient temperature almost does not change much after the temperature of the aluminum ball CT reaches a steady state, resulting in almost negligible influence of the ambient temperature on the cooling index of the aluminum ball.

Based on the calculation results of cooling index shown in Table 1, equation (18) is used to calculate the conductor ampacity (the conductor LGJ-240/30) under different environmental conditions. The results are shown in Fig. 5.

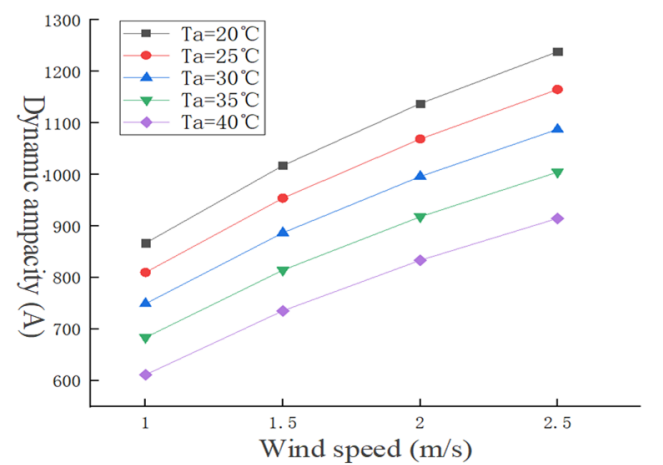

Fig. 5 Dynamic ampacity values under different conditions

In Fig. 5, when the wind speed is constant, the conductor ampacity gradually decreases with the increase of the ambient temperature. When the ambient temperature is constant, the conductor ampacity increases gradually with the increase of the wind speed. Besides, the influence of wind speed on the conductor ampacity is higher than that of ambient temperature. According to GB1179-83, the static ampacity of the conductor model LGJ-240/30 is 445 A. Compared with the static ampacity, the non-contact dynamic capacity-increasing method proposed in this paper has obvious capacity-increasing effect and can excavate the transmission capacity of transmission lines to a large extent.

\section{Conclusions and prospects}

According to the theory of the non-contact dynamic capacity increase, a cooling testing device is designed. By defining the cooling index to represent the heat dissipation ability of the object, a correlation model for the cooling index of conductors and the CT is deduced theoretically, so as to realize the dynamic calculation for the ampacity. The cooling indexes of the CT under different environmental conditions are calculated by means of finite element simulation, and the corresponding conductor ampacity is obtained. The following conclusions can be drawn:

1) The cooling index can represent the heat dissipation ability of an object. The higher the value, the stronger the heat dissipation ability. The cooling index of the CT is positively correlated with the wind speed, but negatively correlated with the ambient temperature. Compared with the influence of wind speed on the cooling index, the influence of ambient temperature on the cooling index is extremely small.

2) The dynamic conductor ampacity is positively correlated with the wind speed, but negatively correlated with the ambient temperature. The influence of wind speed on the conductor ampacity is higher than that of ambient temperature. Compared with the static ampacity, the non-contact dynamic capacity-increasing method based on the CT has obvious capacity-increasing effect. 
3) In the subsequent research work, further study will focus on simplifying and improving the cooling correlation model of the $\mathrm{CT}$ and the conductors and building a non-contact dynamic capacity-increasing experiment platform to verify the cooling correlation model.

\section{Acknowledgments}

This work was supported by the China Southern Power Grid Corporation Science and Technology Project (GDKJXM20185588).

\section{References}

1. Xinbo H and Ronggui C. (2008) Theoretical Study on Dynamic Capacity increase of Transmission Lines. In:2008 International Conference on Condition Monitoring and Diagnosis, Beijing, China. pp.723-6.

2. Fan S, Yanling W, Zhao L, et al. (2019) Study on Thermal Load Capacity of Transmission Line Based on IEEE Standard. J, Journal of Information Processing Systems, 15(3):464-477.

3. Douglass, D.A.; Edris, A.-A. (1996)Real-time monitoring and dynamic thermal rating of power transmission circuits. J, IEEE Transactions on Power Delivery, 11(3):1407-1418.

4. Seppa T. O. (1995) Accurate ampacity determination: temperature-sag model for operational real time ratings. J, IEEE Transactions on Power Delivery, 10(3):1460-1470.

5. Gang L, Banyi Y, Jie L, et al. (2013) Steady-state model of thermal circuit method for dynamic overhead lines rating. J, High Voltage Engineering,39(5):1107-1113(Chinese)

6. Michiorri, A. , Nguyen, H. M., Alessandrini, S. ,et al. (2015) Forecasting for dynamic line rating. J, Renewable and Sustainable Energy Reviews, 52, 1713-1730. 